\title{
Medicina moderna e bioética: fundamentos de uma inconciliação
}

\section{Modern medicine and bioethics: principles of non reconciliation}

\author{
Taylisi de Souza Corrêa Leite \\ Unesp/Franca-SP. Brasil \\ leitetaylisi@gmail.com
}

Resumo: Este texto tem por escopo demonstrar, com o aporte teórico de autores da primeira geração de Frankfurt, que a medicina moderna é um desdobramento da razão, passando pelo cartesianismo, iluminismo, positivismo e tecnicismo. Uma medicina calca da da técnica e na mitificação racional totalitária da modernidade, obrigatoriamente, não conviverá com reflexões éticas, de modo que a proposta de uma bioética no interior dessa razão será sempre inócua. Assim, medicina e bioética são inconciliáveis desde a sua gênese e, passando por seus métodos, até sua teleologia. Para uma medicina ética, portanto, o caminho concreto deveria partir da ruptura com a estrutura racional moderna que lhe dá os contornos.

Palavras chave: medicina, bioética, modernidade, razão.

\begin{abstract}
This paper has the purpose to demonstrate the theoretical authors of the first generation of Frankfurt, modern medicine is an offshoot of reason, through Cartesianism, Enlightenment, Positivism and technicality. A medical technique and grounded in rational mythologizing totalitarian modernity, must not coexist with ethical reflections, so that the proposed bioethics inside this reason will always be innocuous. Thus, medicine and bioethics are irreconcilable since their genesis and, through its methods, even its teleology. For an ethical medicine, so the concrete path should start from the break with the rational structure that gives it modern contours.
\end{abstract}

Keywords: medicine, bioethics, modernity, reason.

\section{Introdução}

A partir do aparecimento e desenvolvimento da bioética, enquanto nova seara da investigação acadêmica, que congrega conhecimentos médicos e biológicos com diversos acúmulos teóricos das humanidades, forjou-se uma percepção hegemônica de que discutir bioética sempre se daria a partir de olhares direcionados a objetos 
específicos. Por isso, as perguntas bioéticas sempre partem de demandas concretas do cotidiano de quem lida com saúde humana, vida e morte. Toda vez que uma nova tecnologia e dilemas éticos aparecem, as perguntas bioéticas passam a ser formuladas, e tanto os conselhos de ética das áreas de saúde quanto o direito positivo estatal procuram sofregamente responder a todas elas.

Desse modo, a bioética vem se desenvolvendo como uma área do conhecimento que cuida justamente de propor todas as perguntas e tentar fornecer respostas e, portanto, apresenta-se como um campo de trabalho e reflexão importantíssimo contemporaneamente. Reconhecemos isso. A questão que ora se coloca é outra: por que a bioética existe e quais as suas possibilidades éticas concretas?

Somente partindo dessa indagação, a nosso ver, é que realmente se poderiam orientar as buscas pelas demais respostas. E a angústia confessada parte, antes de tudo, de que é isso que está faltando para a bioética - ser capaz de enxergar a muralha da razão e compreender qual a sua gênese para entender seus limites e possibilidades.

Eis que, quando nos questionamos acerca do fenômeno bioético na modernidade ocidental recente, a angústia acima relatada doeu. Simplesmente, porque é cristalino que a bioética só existe porque a ciência e a medicina não são éticas. É óbvio que só é preciso edificar uma nova área do conhecimento com aplicação prática chamada "bioética" porque a realidade é antiética; caso contrário, isso seria absolutamente desnecessário. Então, a grande questão aparece: por que as ciências em geral, com destaque para a medicina, nada têm de éticas, convertendo-se, inúmeras vezes, em práticas imorais? É sobre isso que vimos discorrer neste despretensioso texto.

\section{Medicina moderna cartesiana}

A medicina moderna, que começa a ser gestada no século 16, terá seu nascimento no século 18, com o método empírico, abandonando qualquer percepção mítica, para se tornar concreta e racional, até avançar com o positivismo oitocentista à clínica e ao sanitarismo, e se tornar absoluta no século 20, como o discurso unívoco acerca de doença e saúde. 
Certamente, se o objetivo primordial da razão era forjar o empoderamento antropocêntrico do sujeito cognoscente, para o libertar dos grilhões das concepções metafísicas divinas absolutas e inexoráveis, e de uma natureza caótica monstruosa, avassaladora e inelutável, a compreensão do funcionamento do corpo apareceria como tarefa fundamental.

Conquanto, na lógica da razão, que nasce com Descartes, pela qual o conhecimento classificatório está sempre orientado à manipulação, isto é, conhecer para manipular, dominar e transformar, é claro que o conhecimento anatomofisiológico só teria razão de ser a partir da patologia. Anatomia é necessariamente anatomia patológica e fisiologia, fisiopatologia.

Adverte Donatelli (1): “A crítica cartesiana à filosofia especulativa, contida na sexta parte do Discurso do Método, indica que, a partir da utilização de seu método, é possível chegar a conhecimentos úteis à vida de forma que possamos nos tornar mestres e donos da nature$z a^{\prime \prime}$ (p.1). E, por isso, conclui:

Esse domínio da natureza está estreitamente ligado à conservação da saúde: o primeiro bem e o fundamento de todos os outros bens desta vida (Discurso, 6 ${ }^{\mathrm{a}}$ parte). Assim, as aplicações úteis da nova ciência proposta por Descartes estão voltadas para uma medicina que se dirija, efetivamente, para a cura dos pacientes (p.1).

Não teria sentido, sob o condão da razão instrumental, o conhecimento da anatomia e da fisiologia do corpo humano se não fossem apenas substratos de manipulação do funcionamento corpóreo para a cura de moléstias. A doença aparece, portanto, como o elemento natural antes inelutável e mitificado, que poderá ser compreendido, controlado e dominado pelas armas da razão.

Por essa razão, a medicina moderna só tem propósito se for capaz de curar as doenças através de processos racionais analiticamente estruturados. Não há notícias, antes da razão moderna, de concatenação lógica entre práticas clínicas e resultados, que considerem um nexo causal racional entre intervenção e reação, desde um olhar sistêmico sobre o funcionamento do corpo humano. O que havia eram práticas ritualísticas completamente baseadas na crença e num histórico precedente de sucesso, embora certamente atrelado a causas aleatórias. 
O estudo do corpo, que, para ser fidedigno seria também invasivo, só poderia ocorrer com a utilização de cadáveres, o que já encontrará uma barreira monolítica nas crenças religiosas da Antiguidade e, ainda mais, do Medievo. A permissividade de observação cadavérica como mero objeto da investigação racional somente se torna possível num mundo onde o temor aos deuses seja suplantado pela crença firme numa racionalidade que pode suplantar a própria morte.

Por isso mesmo, será com Descartes, que as primeiras investigações modernas sobre anatomia poderão ser realizadas sobre corpos reificados, observados, catalogados e medidos geometricamente. A observação é invasiva, inaugurando-se as técnicas de vivissecção de animais, tratando-se a medicina como um ramo da física. Somente um método que aparte sujeito de objeto é idôneo a coisificar o corpo humano, de modo a torná-lo não identificável com o observador, que se sentirá à vontade para realizar sua pesquisa (1).

Por isso, conclui Donatelli (1): "A ênfase na física justifica-se pelo fato de a medicina ser um de seus ramos e estar embasada em seus princípios (...) a experiência ganha destaque, à medida que as causas vão sendo postuladas a partir daquilo que é observado (...) no caso da medicina, a partir da dissecação ou da vivissecção de animais, como pode ser constatado nas várias anotações anatômicas deixadas por Descartes, nas quais as observações feitas a partir de dissecações e vivissecções estão registradas" (p.1).

A partir do cartesianismo e sua observação geométrica dos contornos corpóreos, uma primeira perspectiva sistêmica surgirá, desde uma percepção completamente matematizada de que o corpo em bom funcionamento é aquele que possui proporções numéricas exatas entre seus diversos elementos, que podem ser separados, classificados e quantificados. A ideia de proporção pressupõe a fragmentariedade corporal, isto é, somente pode ser proporcional o que não pertence à mesma totalidade.

A razão opera com a equanimização do mundo, de modo que o objeto está reduzido às representações que o sujeito cria a seu respeito, numa tentativa neurótica de sistematizar tudo o que existe e enunciar a pretensa verdade sobre as coisas, como um dado eternamente submetido à lógica formal, pois, através da identificação 
antecipada de categorias num mundo totalmente matematizado, o racionalismo acredita que pode escapar do retorno ao mito, ou do pavoroso regresso ao estado de natureza primitivo, já que o formalismo matemático, cuja unidade é o numeral, mantém o pensamento firmemente preso à confortadora abstração imediata.

\section{Medicina moderna iluminista}

Decorrente da matematização da medicina, teremos, no século 17, também, a extrema valorização da astrologia nos cursos médicos. Operando cálculos matemáticos que julgava precisos, o fisiologista saberia determinar qual a influência dos astros sobre as moléstias do corpo e, então, realizar diagnósticos e intervenções pretensamente racionais.

O visual, como a matemática, na modernidade, presta-se a eliminar as ambiguidades, atendendo às exigências de uma razão totalitária. Ou seja, além de eliminar a ontologia identitária, a razão idiotizou a humanidade ocidental. O processo desenvolvido de esclarecimento acabou reificando completamente os sujeitos e tornando-os ineptos para a compreensão gnosiológica.

Posteriormente, a partir do Esclarecimento do século 18, uma nova perspectiva médica se apresenta, em consonância com os novos propósitos da própria razão. O olhar sobre o objeto-corpo não mais se contenta com sua observação externa, suas formas, seus contornos e suas proporções, para mergulhar nas suas vísceras com a finalidade de perscrutar sua lógica de funcionamento interior. A passividade do objeto permite ao observador um olhar que invada suas estruturas mais obscuras, em busca de uma compreensão que possa se converter em manipulação, alteração, domínio e aprimoramento.

Enfim, a perspectiva empírica vai além do visível superficial para, a partir dele, estabelecer uma relação com o invisível logicamente investigável, de modo a devassar o corpo e a doença nele alocada. Isso significa que, para a medicina que surge no século 18, e terá seu auge no século 19, doença e corpo coincidem no mesmo espaço quando este estiver atacado por aquela e, por isso, o estudo da anatomia só faz sentido enquanto anatomopatologia, sob pena de 
ser informação inútil, não instrumental, para a qual não há lugar no reino da razão moderna.

Então, o "são" é tomado como paradigma de contraposição em relação ao "doente", num contexto em que os conceitos de "saúde" e "doença" poderiam ser altamente variáveis conforme as concepções do médico - detentor da verdade. Segundo Adorno (2): "A doença dos sãos só se pode diagnosticar objetivamente na desproporção entre o seu modo de vida racionalizado e a possível determinação racional da sua vida" (p.67).

Com o avanço das técnicas médicas, ainda, desponta a magnitude da cirurgia clínica como intervenção capaz de atacar localmente a patologia, pressupondo, do cirurgião, profundo conhecimento anatômico e plena destreza técnica de manipulação de instrumentos sobre a estrutura corpórea.

O corpo e a moléstia aparecem em uma relação simbiótica, de modo que a cura só se possibilita pela intervenção no lugar exato onde a doença se localiza. O cirurgião é, então, o médico por excelência. Os não cirurgiões passam a ser vistos no universo da medicina como submédicos.

Desde então, o discurso medicalizante da vida mostra-se capaz de ocupar um espaço antes privativo da teologia. O médico sabe sobre o corpo e a doença e é capaz de curar, a partir de pressupostos racionais, assentados sobre paradigmas científicos positivistas capazes de provar as hipóteses, assim como idôneos a provar que seu método de comprovação é verdadeiro.

\section{Medicina moderna positivista e técnica}

O positivismo aplicado à medicina encontra seu casamento mais feliz e promissor, pois não há objeto mais delimitado que o próprio corpo, cuja estrutura é necessariamente universal, isto é, o conhecimento de um único corpo isolado conduz ao conhecimento de todos os corpos humanos, desde que haja um elemento que os identifique. A identificação absoluta ou não dependerá das premissas da razão instrumental.

No desespero da razão esclarecida em nominar o inominável e controlar o inexorável, a aberração ou o desviante funcionam tão- 
somente como estratégias para reforçar os padrões de normalidade vigentes. Então, o "doente" e o "louco" poderão ser medicalizados desde uma linguagem que denomine para capturar o antes incomensurável.

Se é a razão quem determina as verdades e proclama as existências, a partir do momento em que o sujeito que protagoniza o método aloca algo ou alguém no espaço do objeto, estará dissociado dele e o poderá investigar e manipular instrumentalmente. O cartesianismo, incrementado pelo positivismo cientificista, é o que possibilita que pessoas humanas possam ser deslocadas ao lugar do objeto, coisificadas pelo método racional. Ali, poderão ser compreendidas e dominadas como qualquer objeto, em nome do progresso científico, dentro das relações de produção capitalistas.

Há uma cisão obrigatória entre aqueles que se assoberbaram na empáfia da ciência em relação aos que podiam ser objeto de pesquisa típica da modernidade racional. Se a proposta bioética se refere a uma limitação da razão por meio de critérios morais e da proteção ao ser humano, isso não convive com a modernidade capitalista. A bioética, então, na forma de códigos de conduta, jamais passará de um cinismo da razão.

Possivelmente, os cientistas implicados em diversas pesquisas invasivas com seres humanos ao longo do século 20 nem estivessem imbuídos de ódio emotivo, mas, pretensamente neutros como bem prescreve o positivismo, foram capazes de reificar seres humanos enquanto meros objetos de pesquisa em nome do progresso científico. Na cadência da razão embrutecida, cabe qualquer dança da morte, pois o que possibilita o envolvimento de pesquisadores brilhantes e médicos bem formados (para curar) na destruição de seres humanos é o movimento dicotômico e o método analítico da razão instrumental.

Só a modernidade é capaz de forjar um discurso tão perverso e totalitário ao ponto de seres humanos formados para a medicina se sentirem fidelíssimos aos projetos da razão enquanto simplesmente assistem a uma doença brutal devorar corpos humanos, ou quando manipulam corpos vivos para aferir suas limitações e contornos.

O pressuposto do conhecimento científico que parte de uma unidade conceitual e, por isso, pode ser reproduzido, é a abstração, 
que decorre do distanciamento do sujeito em relação ao objeto, mas também do distanciamento dos indivíduos em relação à sua própria natureza e dos múltiplos indivíduos entre si, de modo que a razão esclarecida acaba por desumanizar todas as relações humanas. Dizem, brilhantemente, os teóricos de Frankfurt que (5) “(...) o preço que se paga pela identidade de tudo com tudo é o fato de que nada, ao mesmo tempo, pode ser idêntico consigo mesmo" (p.23). E esse preço pode ficar alto demais. Ironiza Horkheimer (4): "de acordo com os positivistas, precisamos é de abundante confiança na ciência. Claro que eles não estão cegos para os usos destrutivos aos quais se destina a ciência; mas proclamam que tais usos são perversões" (p.64). O que o filósofo pretende demonstrar é que (4) "o progresso objetivo da ciência e sua aplicação, a tecnologia, não justificam a ideia corrente de que a ciência é destrutiva só quando pervertida e necessariamente construtiva quando entendida de modo adequado" (p.64). E, lúcido, irá concluir: (4) "sem dúvida a ciência poderia ser destinada a melhores usos. Contudo, não é de modo algum certo que a via de realização das boas potencialidades da ciência seja a mesma no seu atual caminho" (p.64).

O médico é o sujeito cognoscente, o paciente, passivo, seu objeto. Não cabe bioética nos contornos da medicina moderna. A tecnicização do saber médico, afinal, inviabiliza que esses profissionais podem desenvolver sua própria subjetivação e a reflexão crítica, o que é oportunizado para que se tornem meros operadores de corpos a serviço da estrutura produtiva. O médico moderno é um técnico, preparado para ser neutro ao lidar com o objeto, e qualquer manipulação objetal é plenamente justificável por propósitos maiores (que serão informados pelo status quo).

\section{Medicina moderna e bioética}

Nesse contexto, é claro que, em qualquer dilema possivelmente bioético que possa advir das condutas e procedimentos, quem sempre decidiu foi o médico, imbuído de autoridade, a serviço do pragmatismo, do utilitarismo e da razão. Não sem motivo os pacientes são costumeiramente denominados nos hospitais por um número, ou pelo nome de sua moléstia, pois seu nome pessoal não somente 
é irrelevante, como pode turbar o método analítico e a neutralidade.

Mais do que isso, se os procedimentos médicos não passam de relação mercantil, quanto mais rápido for o atendimento, melhor o nível de produtividade para atender aos auspícios do capital. Por isso, a consulta médica abandonará a anamnese cautelosa e qualquer olhar sobre o paciente enquanto subjetividade complexa. Por essas razões, Jacques Ellul (3) vê, na sociedade técnica, uma total supremacia da imagem sobre a palavra, perfazendo uma "(...) a vitória incondicional do visual e das imagens (...)" (p.6).

Segundo ele, o triunfo da imagem sobre a palavra acaba por engendrar um absoluto empobrecimento da linguagem, eliminando as multiplicidades de ressignificação dos conteúdos das mensagens a partir da subjetividade do receptor. Tal dominação visual do entorno é também o fundamento da técnica, diretamente atrelada à eficácia. Na modernidade, olhar é capaz de apreender o espaço e se apropriar da amplidão, colocando o sujeito no centro do universo; combinando tais imagens, esse sujeito incorpora-se à realidade pelo olhar, mas não como mero coadjuvante - é o protagonista da realidade, o ponto a partir do qual se ordenam o universo e o espaço, tornandose constitutivo de todo o cosmos.

Essa exaltação da imagem se assenhoreia das pessoas de maneira tão perversa, que a aparência se torna a única expressão possível de sua subjetividade no mundo, supervalorizada ao ponto de gerar intervenções cirúrgicas drásticas nos corpos, geralmente, consoante os padrões estéticos da indústria cultural. Esse é um dos fenômenos que irá impactar a bioética, mas não o único. Um indivíduo completamente dessubjetivado encontra severas dificuldades em valorar bens como "vida" e "saúde", dissociados de discursos fetichizantes externos.

O homem formado pelo meio técnico necessita viver de imagens. "A progressão técnica é coextensiva à representação visual. Urge que o homem seja polarizado pelo visual para tornar-se um homem técnico"(p.150) (3). Assim, o império da imagem constrói-se na esteira do totalitarismo da racionalidade instrumental, que destitui o valor de tudo o que não tem um fim externo a si, pois o desinteresse pela literatura e a negação da filosofia também passam pela impossibilidade de as transformar em diagramas, em imagens acessíveis 
e apreensíveis.

É com essa tônica que a medicina moderna vai se desenvolver. E vai avançar no século 20, através de uma compreensão sistêmica muito mais aprofundada do funcionamento biológico, com seus gráficos, imagens diagnósticas e exames quantitativos.

A tarefa do médico, técnico, é consertar a máquina (corpo) quando esta apresentar problemas, para restituí-la o mais rápido possível ao mercado, voltando a funcionar como engrenagem do sistema produtivo. Com o desenvolvimento de equipamentos diagnósticos precisos, a tarefa ficou fácil: basta requerer as análises clínicas, que trarão dados matemáticos acerca dos níveis compatíveis com os padrões normais de funcionamento, bem como imagens diagnósticas.

Munido disto, o médico indicará o medicamento alopático a ser adquirido como mais uma mercadoria, e o problema se resolve. Segundo Oliveira e Oselka (6), “O médico de hoje é um simples prestador de serviços rápidos. O cidadão chega lá e fala: 'Estou com o ombro doendo e quero consertá-lo'. Por sua vez, o profissional se limita a arrumar o tal ombro, sem ver este ser humano como um todo, sendo ele representado exclusivamente pelo ombro doente" (p.72).

Esse despudor do médico em se converter num mecânico de corpos deve-se claramente à compartimentação racional do corpo, à dissociação cartesiana do chamado "objeto", ao mito da neutralidade e a outras características típicas do racionalismo, mas deve-se também ao fato de que o médico tem por maior objetivo auferir capital. Isso não pode ser ignorado e estende-se a todos os profissionais da saúde.

Se o atendimento médico está reduzido exclusivamente a uma atividade mercantil (em forma de venda de serviço equiparado à forma da mercadoria), quanto mais rápida a consulta, melhor. Primeiro, porque gera mais produtividade e mais circulação desse serviçomercadoria para atender à demanda.

Como todo trabalhador que ganha por produtividade, quanto mais produzir em menos tempo, melhor será recompensado em remuneração. Se ganhar por jornada, será cobrado na rapidez para produzir mais e causar menos prejuízo para quem investe no produto.

Médico e paciente não são seres humanos que possam se rela- 
cionar, mas apenas sujeito cognoscente e objeto cognoscível, técnico e máquina, prestador de serviços e consumidor. Daí a terminologia "paciente" para designar algo - e não alguém - totalmente apassivado diante de um processo de cura que será empreendido pelo detentor da razão médica. Pior do que esse termo, talvez seja o mais atual: "cliente". Fruto da razão cínica, sem pudores, explicita a relação entre médico e doente como mera relação mercantil. Por isso, "o tabu de falar só de assuntos profissionais e a incapacidade de conversa recíproca são, na realidade, a mesma coisa. Porque tudo é negócio, nada de mencionar o seu nome, como acontece com a corda na casa do enforcado" (p.32) (2).

Segundo Adorno (2),

por detrás da pseudodemocrática supressão das fórmulas do trato, da cortesia antiquada, da conversação inútil e nem sequer injustificadamente suspeita de palavreado, por detrás da aparente claridade e da transparência das relações humanas que não toleram qualquer indefinição, anuncia-se a nua crueza (p.32).

Os pacientes não podem ser tratados como pessoas nunca, pois isso prejudica o negócio e o sucesso da intervenção positiva. Um primeiro dilema bioético, atinente à relação médico-paciente, que seria a desumanização dos tratamentos ou cuidados paliativos no processo de morte sempre encontrará um empecilho inelutável - o médico não pode olhar para seu objeto como um humano semelhante. Desde este aspecto, só a refundação da razão seria idônea a permitir o desenvolvimento bioético.

A concatenação entre a aporia ética da medicina racional e o avanço tecnológico nos conduz, ainda, a outros dilemas bioéticos insurgentes: em nome do progresso, do capital, ou de qualquer ideologia hegemônica, a tecnologia pode-se converter nas maiores atrocidades que a humanidade já presenciou.

Corremos o risco de sermos convertidos em uma sociedade de clones, geneticamente manipulada, composta por ciborgues e submetida à melhorias eugênicas ditadas pela industria cultural (ou tudo isso simultaneamente). Mais desenvolvida, a medicina não 
mais localizará a doença no corpo, mas poderá isolar os agentes patogênicos, tornando-se capaz de desenvolver vacinas para quase todas as moléstias e medicamentos, como a penicilina, e outros mais complexos, que partem da compreensão da biologia viral e bacteriana.

Aí se situam os que se chamam dilemas bioéticos insurgentes. Essas descobertas e inovações irão movimentar um mercado milionário, fortalecendo nosso argumento de que a biotecnologia não passa de um processo de produção industrial. Dizia Grisolla já há onze anos (7): "Os antibióticos microbianos, substâncias farmacêuticas, assim como os novos produtos da biotecnologia, tal como o DNA polimerase termestável, já têm um valor comercial estimável em 500 milhões de dólares por ano" (p.17). Calcule-se isso nos dias presentes.

Ocorre que, certamente, esses tratamentos e equipamentos diagnósticos não estão disponíveis para todos os seres humanos do planeta, ao contrário, são para pouquíssimos privilegiados. A ciência e a tecnologia (que inclui biotecnologia) são instrumentos neutralizados pelo positivismo para poderem se comprometer com a manutenção da ordem.

Além disso, inscrevem-se entre os processos de produção e obedecem à lógica de mercado. Isso significa que não se pode olhar para a medicina instrumental sem ter em conta que seu compromisso não é com a saúde de todos os seres humanos, mas com as estruturas vigentes em nossa sociedade, que correspondem, fundamentalmente, a tudo o que interessa ao sistema econômico capitalista. Trata-se de uma constatação elementar. O que fomentou o desenvolvimento médico, com todas as novas técnicas e descobertas acima referidas não foi o compromisso com a vida ou a saúde, mas a reprodução do capital e a salvaguarda dos corpos abastados. Pondera Horkheimer (4): "A ciência hoje, sua diferença de outras forças e atividades sociais, sua divisão em áreas específicas, seus procedimentos, conteúdos e organização, só podem ser entendidos em relação com a sociedade para a qual ela funciona" (p.64).

Eis que inúmeras doenças tropicais, que só acometem populações miseráveis de países pobres, como a malária, a dengue e a doença de chagas, serão absolutamente negligenciadas (8) pelas 
pesquisas científicas sobre vacinas e medicamentos, ao passo que outros males, que acometem populações abastadas também, terão profilaxias e medicinas bastante desenvolvidas.

Essa eletividade nada tem a ver com a complexidade da moléstia, mas com a instrumentalização capitalista dos tratamentos. E, ainda que haja desenvolvimento científico, os avanços não alcançam a todos, de modo que, por exemplo, em 2011, mais de meio milhão de crianças morreram vítimas de sarampo (doença cuja vacina foi desenvolvida em 1963), a imensa maioria na Ásia e na África (9).

Em quaisquer periferias do planeta, incluindo o Brasil, é patente que, em pleno século 21, não há sequer saneamento básico, com tratamento de água e esgoto, como preconizavam os sanitaristas oitocentistas, muito menos há disponibilidade de medicamentos protegidos por patentes de grandes laboratórios transnacionais e equipamentos diagnósticos sofisticados à população carente. Todas essas maravilhas do avanço tecnológico estão em hospitais privados caríssimos para as pessoas abastadas, mas não estão nos rincões do planeta. Aí se situam os grandes dilemas bioéticos a que se chamarão problemas bioéticos persistentes.

O esvaziamento ético dos próprios profissionais de saúde (principalmente, os médicos, por sua autoridade discursiva e sua ascendência, inclusive, sobre outros profissionais) e cientistas, totalmente rendidos à razão instrumental, fará com que esses profissionais não estejam aptos a tratar com humanidade as demandas bioéticas que se apresentarem a eles.

Além disso, as maravilhas do progresso científico sempre estarão disponíveis apenas para os mais ricos e, até hoje, predominantemente, brancos.

Ressaltamos que priorizamos discursar sobre os impactos da razão na medicina e nos médicos, mas não ignoramos a importância dos demais profissionais da saúde no atendimento e tratamento de pessoas, como enfermeiros, auxiliares e técnicos de enfermagem, odontologistas, fisioterapeutas, fonoaudiólogos, psicólogos, farmacêuticos, entre outros.

Ocorre que os médicos costumam tratar esses profissionais como seus meros assistentes, a eles subordinados; assoberbados pelo domínio pleno da razão que lhes confere conhecimento e poder so- 
bre os corpos, buscarão ascendência sobre todos seus colaboradores, acreditando que a intervenção destes últimos não passa de um adendo ao tratamento principal ou de um instrumento deste.

Não é sem motivo que os médicos vão pelejar pelo ato médico, buscando impedir que quaisquer outros profissionais atuem naquilo que consideram seu domínio exclusivo - sob a justificativa de que apenas eles detêm o saber necessário. Além disso, ainda intentam poder prescrever o trabalho desses outros atores; "prescrevem" sessões de fisioterapia, fonoaudiologia, psicologia, entre outras, como prescrevem medicamentos, como se não fosse competência de cada um destes profissionais fazer sua própria triagem e decidir se sua intervenção é necessária.

Subservientes ao absolutismo médico, esses profissionais vão reproduzir as mesmas agruras cartesianas que forjaram o biosaber, ainda mais porque sua formação também se deu sob os auspícios da razão, convertendo seu labor em técnica que busca resultados eficientes de cura. Nesse passo, diante da ausência de medicamentos e equipamentos disponíveis para todos, que critérios os profissionais de saúde irão utilizar para selecionar os beneficiados? O critério acima do critério é sempre socioeconômico. Então, se não há o recurso disponível para pobres, o critério já foi pré-estabelecido.

Entretanto, mesmo se houver o recurso disponível e o profissional da saúde puder decidir, provavelmente, adotará critérios puramente utilitaristas, priorizando jovens a idosos, por exemplo (porque aqueles ainda podem contribuir por mais tempo para o sistema, pela exploração do trabalho), ou poderá haver cenários piores, porque a razão cartesiana já se mostrou capaz de colocar negros e judeus no lugar do outro não-sujeito.

O médico deve ser sempre neutro, o que, certamente, reduz sua responsabilidade em face daquele que medica; ao invés de tomar em conta que lida com uma vida humana concreta, com uma pessoa que possui nome, sonhos e esperanças, passa a lidar unicamente com a doença, operando a melhor técnica. Se falhar, não falha com um ser humano semelhante a si; falha tecnicamente. Os demais profissionais da saúde reproduzem esse mesmo método. Por sua vez, o doente exime-se de protagonizar seu próprio processo de doença e morte, para submeter-se ao paternalismo vertical de um médico que tudo sabe. 
Portanto, não se responsabiliza pelas escolhas que são feitas para intervir sobre seu corpo e por seus resultados.

\section{Considerações Finais}

Desde que, no alvorecer da modernidade, os questionamentos abandonados no medievo converteram-se em mote para o empoderamento do humano perante forças que pareciam inexoráveis (porque incompreensíveis e avassaladoras, ou porque vinculadas a uma vontade divina absoluta e intangível), a razão infundiu, em cada indivíduo moderno, uma sensação de plenitude. Dali em diante, não seria mais necessário se submeter às intempéries e variações da natureza, nem se conformar com uma condição de submissão a uma divindade invisível. As doenças puderam ser compreendidas e, consequentemente, combatidas. O homem se viu dotado de tanto poder que era capaz de vencer a própria morte, através das armas da razão. Floresce a medicina da razão, símbolo do heroísmo racional moderno. Surgia uma nova era, em que o protagonismo seria todo humano.

Tanto deslumbramento com a razão fez com que ela pudesse, gloriosa, ocupar o trono que antes era do deus único do cristianismo medieval, e a mesma voz que proclamava o cientificismo pregava a religião positivista. Enfim, com a razão endeusada e a ciência propaladora de verdades absolutas sobre toda a existência, o progresso chegou em definitivo, até que, hoje, possamos manejar ferramentas tecnológicas antes inimagináveis, alterando o corpo humano, como milagre ou magia, para os quais, no entanto, a explicação é racional. A razão é deus, o milagre, a magia e a religião. Contudo, não há nada de mágico no mundo moderno. Esse conto fantástico da razão tem um anverso. E é ele que vai originar a bioética.

Para conseguir cumprir essa tarefa com máxima eficiência, separou sujeito e objeto, impediu que os sujeitos valorassem o objeto, afastou qualquer emotividade de olhar desse sujeito sobre o mundo, negou a metafísica, desidentificou sujeitos em relação à natureza e entre si, promoveu o absoluto individualismo, fomentou a frieza, converteu todo o raciocínio em análise e quantificação técnica, matou a crítica, acabou com a reflexão e impossibilitou qualquer ética. Essa é a velocidade do progresso moderno. 
Um sujeito reprodutor dessa razão é individualista, alienado, sonâmbulo. O filho da razão é, por isso, como o médico e o monstro. Se, por um lado, é brilhante, civilizado, racional, profundo conhecedor da ciência, capaz de empreender ordem e progresso, por outro, é limitado, egoísta, frio, embrutecido, acrítico, incapaz de olhar o outro com amor, e capaz de cometer as mais monstruosas atrocidades em nome da razão. Esse será o sujeito que protagonizará a barbárie. Auschwitz, as guerras, o genocídio, a fome e inumeráveis outras barbaridades só foram e são possíveis porque perpetradas pelos filhos da razão. A despeito da metáfora, obviamente, isso não é um privilégio dos médicos, mas medicina e direito protagonizam com papel destacado todas essas atrocidades, com destaque também significativo para os juristas neutralizados reprodutores de perversidades.

De um lado, a bioética surge decorrente do avanço da razão, que foi capaz de devassar o corpo e a natureza e empreender extrema tecnologia, isto é, de um lado, a bioética surge devido aos auspícios da razão, de suas maravilhas. De outro, porém, a bioética só aparece justamente porque essa razão precisou eliminar a ética e qualquer subjetivação ontológica para prosperar, isto é, a bioética deve-se, deste lado, à perversidade da razão totalitária, embrutecedora, técnica e instrumental a serviço do sistema capitalista.

Ocorre que o pensamento esclarecido não admite o estranho, o transbordante, o não-idêntico e o desviante - e este é um de seus atributos mais fundamentais. Porquanto, para admitir discursos bioéticos e de direitos humanos em seu interior, adaptou-o às suas estruturas, conferindo-lhes status de ciência autônoma ou de ramo de uma ciência, e os convertendo em técnicas, paradigmas, normas ou teorias de aplicação de normas.

Os impactos que a razão causa sobre a medicina são monumentais. Afirmativamente, a medicina racional trouxe incontáveis avanços para a humanidade. A possibilidade de compreensão do funcionamento do corpo colocada a serviço da prevenção e tratamento de doenças trouxe longevidade aos seres humanos, melhores condições de saneamento, maior qualidade de vida e menor sofrimento. Há que se reconhecer e comemorar tudo isso.

Entretanto, há que se ter em conta que essas vantagens são gozadas por apenas uma parte da humanidade, já que tudo isto está 
convertido em mercadoria e inserto em um sistema econômico que só se mantém pela abissal desigualdade de acesso ao capital e, consequentemente, às mercadorias. Ademais, todas essas conquistas vieram acompanhadas de alguns contornos.

Entre eles, sinalizamos a perda de humanidade dos manipuladores da razão, dentre os quais se destacam os médicos. Para poder chegar a este nível de desenvolvimento científico que temos hoje, a razão percorreu um trajeto calamitoso, no qual cada desvio e cada obstáculo foram removidos com presteza e violência. Para se manter firme em uma única direção (direção a si mesma), a razão técnica construiu seu caminho e seu veículo, bem como todas as regras do percurso. Por isso, insistimos em tratar razão e técnica como sinônimas.

Autorreprodutoras, só chegam a um nível mais elevado por um trajeto que elas mesmas projetam, e assim avançam acima e além, progressivas. Porque elimina qualquer possibilidade desviante para ser absoluta, o racionalismo acaba eliminando tudo o que não se inscreve na frieza técnica, ou seja, acaba eliminando também a capacidade humana de sentir empatia, afeto, compaixão, amor etc., pois qualquer emotividade é considerada desvio, e não pode ser incorporada aos processos racionais.

Elementarmente, o positivismo é o corolário da razão ao propagar a neutralidade científica (que significa desumanização do cientista em última análise). Por certo que um médico neutralizado não pode sentir nada daquilo por seu objeto paciente e, como a razão não cessa de avançar, isto, levado adiante e além, converte-se em práticas médicas bárbaras, com os infindáveis exemplos históricos que nos relegou o século 20. Num cotidiano mais comezinho, mas não menos catastrófico, virá a ser a relação fria que médicos realizam com as pessoas que tratam todos os dias em busca de resultados técnicos e, acima disso, de capital.

É claro que isto não está presente nas intenções axiológicas de cada sujeito que escolhe ser médico, mas todos têm imensa dificuldade de escapar a essas amarras porque esses são os limites que a razão traçou para sua atuação e já relatamos a dificuldade de suplantar a muralha. Ainda, é preciso enfatizar repetidamente que não olvidamos a existência de diversos outros profissionais da saúde que também lidam com demandas bioéticas. 
Sabemos que não se trata apenas de médicos. Todavia, ocorre que os médicos, empoderados pela razão, colocam-se em posição superior também aos seus colaboradores (e não só aos pacientes). Tradicionalmente, tratam todos os outros profissionais como meros serviçais auxiliares, pois, no imaginário médico racional, o médico é o herói, o protagonista do combate à doença vilã.

Ademais, a medicina será aquela que invocará a razão e todos os seus métodos para dominar e controlar a natureza (corpórea), através de técnicas instrumentais por excelência.

Isso não quer dizer que a perversidade racional não esteja nas outras ciências, com destaque para a farmacologia, as quais porém, são também todas manipuladas pelo médico e ensinadas nas escolas de medicina.

Queremos demonstrar, tão-somente, que a medicina, como qualquer braço da razão, precisa ser desumana para operar com eficiência; então, desejar que os profissionais atuem com bioética é um contrassenso, por mais esforço que façam os conselhos de ética para produzir normatizações e orientações deontológicas nesse sentido. Não há ética na razão instrumental em vigor. Então, voltamos para uma de nossas conclusões centrais: para que haja alguma bioética é preciso refundar a razão.

\section{Referências}

1. Donatelli MC de OF. Descartes e os médicos. Scientiae studia; São Paulo jul/set 2003; 1(3):323-336.

2. Adorno ThW. Minima moralia. Tradução de Artur Mourão. Lisboa: Edições 70;1982.

3. Ellul J. A palavra humilhada. São Paulo: Edições Paulinas;1984.

4. Horkheimer M. Eclipse da razão. Tradução de Sebastião Uchoa Leite. São Paulo: Centauro;2007.

5. Adorno TW, Horkheimer M. Dialética do esclarecimento: fragmentos filosóficos. Tradução de Guido Antonio de Almeida. Rio de Janeiro: Zahar;2006.

6. Oselka GW, Oliveira RA. Conflito de interesses em pesquisa clínica. São Paulo: CREMESP: Centro de Bioética;2007.

7. Grisolla S. A biotecnologia no terceiro milênio. In: Casabona CMR. (Org.). Biotecnologia, direito e bioética: perspectivas em direito comparado. Belo Horizonte: Del Rey;2002.

8. OMS. Doenças Tropicais Negligenciadas- DTN. Disponível em http://www.senado.gov.br/comissoes/cas/ap/AP_20080604_Doencas_ Negligenciadas.pdf (acesso em 20/set/2012). 
Revista Brasileira de Bioética 2015;11 (1-4):115-133

9. Médicos Sem Fronteira Notícias. "Sarampo". Disponível em http:// www.msf.org.br/conteudo/21/sarampo/ (acesso em 20/set/2012).

Recebido em: 09/04/2015 Aprovado em: 20/07/2015 